\title{
Diagnostic value of ultrasound combined with magnetic resonance imaging in different stages of breast cancer
}

\author{
QIAOHONG PAN ${ }^{1^{*}}$ and JIANWU JI ${ }^{2 *}$ \\ Departments of ${ }^{1}$ Ultrasound and ${ }^{2}$ MRI, Heping Hospital Affiliated to Changzhi Medical College, \\ Changzhi, Shanxi 046000, P.R. China
}

Received August 2, 2018; Accepted September 28, 2018

DOI: $10.3892 / \mathrm{ol} .2018 .9589$

\begin{abstract}
Diagnostic value of ultrasound (US) and magnetic resonance imaging (MRI) in breast cancer were investigated. One hundred and forty breast cancer patients diagnosed in Heping Hospital Affiliated to Changzhi Medical College from June 2016 to June 2018 were collected, used as breast cancer group, 80 patients with benign breast tumor in the same period were the benign group. Pathological results were used to compare the diagnostic coincidence of US and MRI in breast cancer patients. The positive expression case rates of estrogen receptor and progesterone receptor were significantly higher in breast cancer group than those in benign group, but that of human epidermal growth factor receptor 2 (Her-2) was significantly lower in breast cancer group than that in benign group (all $\mathrm{P}<0.05)$. The sensitivity $(\mathrm{SEN})$ of MRI alone and that of US combined with MRI were higher than that of US alone $(\mathrm{P}<0.05)$. The specificity $(\mathrm{SPE})$ of MRI alone was lower than that of US alone and US combined with MRI $(\mathrm{P}<0.05)$. The NPV of US combined with MRI was significantly higher than that of US alone $(\mathrm{P}<0.05)$. The Youden index $(\mathrm{YI})$ of US combined with MRI was significantly higher than that of US alone and MRI alone. In the diagnosis of N2, that of US combined with MRI was significantly higher than those of US alone and MRI alone $(\mathrm{P}<0.05)$. In stages of M0 and M1 among three methods, those of MRI alone and US combined with MRI were higher than that of US alone $(\mathrm{P}<0.05)$. US combined with MRI for the diagnosis of breast cancer has higher SEN and SPE, with better accuracy rate for the identification of each stage. Reducing the incidence of missed diagnosis and misdiagnosis that may be caused by single diagnosis and
\end{abstract}

Correspondence to: Dr Jianwu Ji, Department of MRI, Heping Hospital Affiliated to Changzhi Medical College, 110 Yan'an South Road, Changzhi, Shanxi 046000, P.R. China

E-mail:w3r27f@163.com

*Contributed equally

Key words: ultrasound, magnetic resonance imaging, breast cancer, diagnosis, TNM staging treatment, it is conducive to clinical screening and guiding clinical symptomatic treatment.

\section{Introduction}

Breast cancer is a gynecological malignant tumor caused by hormone secretion imbalance, nutritional imbalance, viral stimulation, radiation factors and genetic background (1). As social life rhythm accelerates and working methods change, the incidence of breast cancer has increased year by year, which has already ranked first in the incidence of female malignant tumors, seriously threatening women's physical and mental health. The clinical manifestations of breast cancer are mainly orange-like changes in the skin and contour of the breast, with lumps in the breast, nipple discharge and swollen lymph nodes (2). Its early cure rate is extremely high, so early detection and early diagnosis are very important for its prognosis. Moreover, different stages of breast cancer are treated differently. Therefore, the accurate diagnosis of different stages is also very important for breast cancer treatment. With the development and improvement of imaging technologies such as ultrasound (US) and magnetic resonance imaging (MRI), imaging methods have played an increasingly important role in the diagnosis of breast cancer $(1,3)$. At present, TNM staging is the main staging method of breast cancer (4). Currently, physical means, physical examination and molybdenum palladium are mainly used for staging clinically, with not enough sensitivity (5). Both US and MRI are commonly used imaging methods for the early diagnosis and staging of breast cancer. There are studies on the clinical value of MRI combined with US in the diagnosis of breast cancer staging, but most studies are on $\mathrm{T}$ staging, with few studies on $\mathrm{N}$ and $M$ staging (6,7). Therefore, in this study, the diagnostic value of US combined with MRI in the T, N and M staging of breast cancer was analyzed, in order to provide a more effective, sensitive and accurate detection program for the early diagnosis and accurate staging, improving the efficacy of patients' subsequent treatment and the prognoses.

\section{Patients and methods}

Research subjects. A total of 140 breast cancer patients diagnosed in Heping Hospital Affiliated to Changzhi Medical College (Changzhi, China) from June 2016 to June 2018 were 
collected, studied as the breast cancer group, 80 patients with benign breast tumor treated in Heping Hospital Affiliated to Changzhi Medical College in the same period were the benign group. Tumor size, breast cancer classification and other tumor lesions and the diagnosis of breast cancer are subject to pathological results. Inclusion criteria of the breast cancer group were: those confirmed as breast cancer by pathology; females $>18$ years old; those who signed the informed consent form. Exclusion criteria of the breast cancer group were: those with severe fungal bacterial virus infections; those with other severe basic diseases such as heart, liver and kidney; those with mental illness and mental disorders; MRI and US contraindications; pregnant or lactating women; those with incomplete clinical data; those unsatisfied with US and MRI examination images acquired; those with incomplete pathological histological data; those who had received any breast cancer-related treatment within 3 months. Inclusion criteria of the benign group were: those with clinical symptoms such as painless lump, nipple discharge and nipple change; those diagnosed as benign breast tumor by pathology and clinical palpation; females $>18$ years old; those who signed the informed consent form. Exclusion criteria of the benign group were: those with severe fungal bacterial virus infections; those with other severe basic diseases such as heart, liver and kidney; those with mental illness and mental disorders; MRI and US contraindications; pregnant or lactating women; those with incomplete clinical data; those unsatisfied with US and MRI examination images acquired; those with incomplete pathological histological data. This study has been approved by the Ethics Committee of Heping Hospital Affiliated to Changzhi Medical College.

Examination time. The breast lump tissue was surgically resected for pathological examination, and US and MRI were performed at 1 week before operation. US, MRI and the combination of the two were used to confirm the diagnosis of breast cancer, and then the TNM staging was perform of the confirmed pathology.

US examination. The Antares US diagnostic apparatus (Beijing Oriental Mairun Medical Devices Co., Ltd., Beijing, China) has a probe frequency of 8-15 MHz. The two-dimensional US was used to first investigate the shape, size, margin, internal posterior echo and internal calcification of the lesion for judging benign and malignant according to the BI-RADS standard. The Color Doppler Flow Imaging (CDFI) was used to observe the blood flow distribution inside and around the lesion, with a blood flow resistance index (RI) of malignant lesions of $\geq 0.70$. Either the two-dimensional US or CDFI detected the lesion as malignant and that was diagnosed as breast cancer.

MRI examination. A 5T magnetic resonance scanner (Shenzhen Siemens Magnetic Resonance Co., Ltd., Shenzhen, China) and a bilateral breast surface coil were used in MRI, with a contrast agent as gadodiamide injection (Shanghai General Electric Pharmaceutical Shanghai Co., Ltd., Shanghai, China; SFDA approval number: J20140164). MRI scan was used to observe the shape, margin and internal structure of the tumor, and breast cancer scan showed more lobulated or burr signs. The low signal of T1WI and high signal of T2WI, with uneven
Table I. Criteria of T, N and M staging.

\begin{tabular}{ll}
\hline Staging & \multicolumn{1}{c}{ Tumor conditions } \\
\hline T staging & \\
Tis in situ carcinoma & No palpable lump in the breast \\
T1 & Maximum diameter of tumor: $<2 \mathrm{~cm}$ \\
T2 & Maximum diameter of tumor: $2-5 \mathrm{~cm}$ \\
T3 & Maximum diameter of tumor: $>5 \mathrm{~cm}$ \\
T4 & Regardless of tumor size, it has \\
& already invaded the chest wall or skin
\end{tabular}

$\begin{array}{ll}\text { N staging } & \text { No palpable regional lymph node } \\ \text { N0 } & \text { Ipsilateral axillary lymph nodes } \\ \text { N1 } & \text { swollen with activity } \\ & \text { Ipsilateral axillary lymph nodes } \\ \text { N2 } & \text { swollen, fused to each other and } \\ & \text { even adhered to other tissues } \\ & \text { Ipsilateral internal mammary } \\ \text { N3 } & \text { lymph nodes with metastasis }\end{array}$

M staging

M0 No distant metastasis

M1 Distant metastasis including lymph node metastasis on ipsilateral clavicle

internal signal, were the enhanced performance of the 'mesh' or 'island' MRI enhanced scanning for observing the tumor. The breast cancer lump showed a ring-enhanced change.

TNM staging. The breast lump tissue was surgically resected for pathological examination, and breast cancer was staged according to the TNM staging (8). The T staging is mainly based on tumor size, $\mathrm{N}$ staging on the swollen regional lymph node and metastasis, and $\mathrm{M}$ staging on the distant metastasis of the tumor. The criteria of T, N and M staging are shown in Table I.

Comparison indicators. Pathological results were used as the gold standard to compare the diagnostic coincidence of US and MRI in breast cancer patients in different stages of T, N and M. The sensitivity (SEN), specificity (SPE), negative predictive value (NPV), positive predictive value (PPV) and Youden index (YI) of each group were compared. YI = SEN + SPE -1 .

Statistical analysis. SPSS19.0 software system (IBM, SPSS, Chicago, IL, USA) was used for data analysis. Measurement data were expressed as mean $\pm \mathrm{SD}$ and tested by t-test. Count data were expressed as $\%$ and tested by Chi-square test. The level of significance is $\alpha=0.05$.

\section{Results}

General clinical data of patients. There was no difference between breast cancer group and benign group in general clinical data such as age, menopausal status, lesion size and number and tumor site $(\mathrm{P}>0.05)$, but significant differences in the expression of estrogen receptor (ER), progesterone 
Table II. General clinical data of patients.

\begin{tabular}{|c|c|c|c|c|}
\hline Clinical data & $\begin{array}{l}\text { Breast cancer } \\
\text { group }(\mathrm{n}=140)\end{array}$ & $\begin{array}{l}\text { Benign group } \\
\quad(\mathrm{n}=80)\end{array}$ & $\chi^{2}$ value & P-value \\
\hline Age & $35.34 \pm 16.54$ & $32.13 \pm 13.24$ & 1.577 & 0.117 \\
\hline Menstrual status [n (\%)] & & & 2.020 & 0.155 \\
\hline Before menopause & $110(78.57)$ & $56(70.00)$ & & \\
\hline After menopause & $30(21.43)$ & $24(30.00)$ & & \\
\hline Lesion size $(\mathrm{cm})$ & $0.42-5.44$ & $0.59-5.22$ & 0.229 & 0.819 \\
\hline Lesion number [n (\%)] & & & 7.356 & 0.007 \\
\hline Single lesion & $74(52.86)$ & $56(70.00)$ & & \\
\hline Multiple lesions & $66(47.14)$ & $24(30.00)$ & & \\
\hline Tumor site & & & 0.094 & 0.759 \\
\hline Left breast & $74(52.86)$ & $44(55.00)$ & & \\
\hline Right breast & $66(47.14)$ & $36(45.00)$ & & \\
\hline ER & & & 36.780 & $<0.001$ \\
\hline Negative & $49(35.00)$ & $62(77.50)$ & & \\
\hline Positive & $91(65.00)$ & $18(22.50)$ & & \\
\hline PR & & & 6.890 & 0.009 \\
\hline Negative & $60(42.86)$ & $49(61.25)$ & & \\
\hline Positive & $80(57.14)$ & $31(38.75)$ & & \\
\hline Her-2 & & & 55.210 & $<0.001$ \\
\hline Negative & $92(65.71)$ & $11(13.75)$ & & \\
\hline Positive & $48(34.29)$ & $69(86.25)$ & & \\
\hline $\begin{array}{l}\text { Pathological classification }[\mathrm{n}(\%)] \\
\text { (WHO classification criteria for breast cancer) }\end{array}$ & & & - & - \\
\hline Invasive ductal carcinoma & $32(22.86)$ & - & & \\
\hline Intraductal carcinoma & $20(14.29)$ & - & & \\
\hline Medullary carcinoma & $5(3.57)$ & - & & \\
\hline Papillary carcinoma & $36(25.71)$ & - & & \\
\hline Simple carcinoma & $33(23.57)$ & - & & \\
\hline Apocrine carcinoma & $14(10.00)$ & - & & \\
\hline
\end{tabular}

receptor (PR) and human epidermal growth factor receptor 2 (Her-2). The positive expression case rates of ER and PR were significantly higher in breast cancer group than those in benign group, but that of Her-2 was significantly lower in breast cancer group than that in benign group (all $\mathrm{P}<0.05$ ) (Table II).

Comparison of breast cancer diagnosis between US and MRI. Among 140 patients diagnosed as breast cancer by pathology, 107 patients were diagnosed by US, 125 patients by MRI and 129 patients by US combined with MRI (+). Specific results are shown in Table III. The SEN of MRI alone was not different from that of US combined with MRI $(\mathrm{P}>0.05)$, but that of MRI alone and US combined with MRI was higher than that of US alone $(\mathrm{P}<0.05)$. The SPE of US alone was not different from that of US combined with MRI $(\mathrm{P}>0.05)$, but that of MRI alone was lower than that of US alone and US combined with MRI $(\mathrm{P}<0.05)$. The difference in the PPV among the three methods was not statistically significant $(\mathrm{P}>0.05)$. The NPV of US alone and US combined with MRI was not different from that of MRI alone ( $\mathrm{P}>0.05)$. The NPV of US combined with MRI was significantly higher than that of US alone $(\mathrm{P}<0.05)$.
Table III. Results of US, MRI and pathology for breast cancer diagnosis.

\begin{tabular}{lrcr}
\hline $\begin{array}{l}\text { US/MRI } \\
\text { detection results }\end{array}$ & $\begin{array}{c}\text { Pathology } \\
\text { results (+) }\end{array}$ & $\begin{array}{r}\text { Pathology } \\
\text { results (-) }\end{array}$ & Total \\
\hline US (+) & 107 & 17 & 124 \\
US (-) & 33 & 63 & 96 \\
Total & 140 & 80 & 220 \\
MRI (+) & 125 & 29 & 154 \\
MRI (-) & 15 & 51 & 66 \\
Total & 140 & 80 & 220 \\
US combined with MRI (+) & 129 & 13 & 142 \\
US combined with MRI (-) & 11 & 67 & 78 \\
Total & 140 & 80 & 220 \\
\hline
\end{tabular}

The YI of US combined with MRI was significantly higher than that of US alone and MRI alone, and that of US alone was 


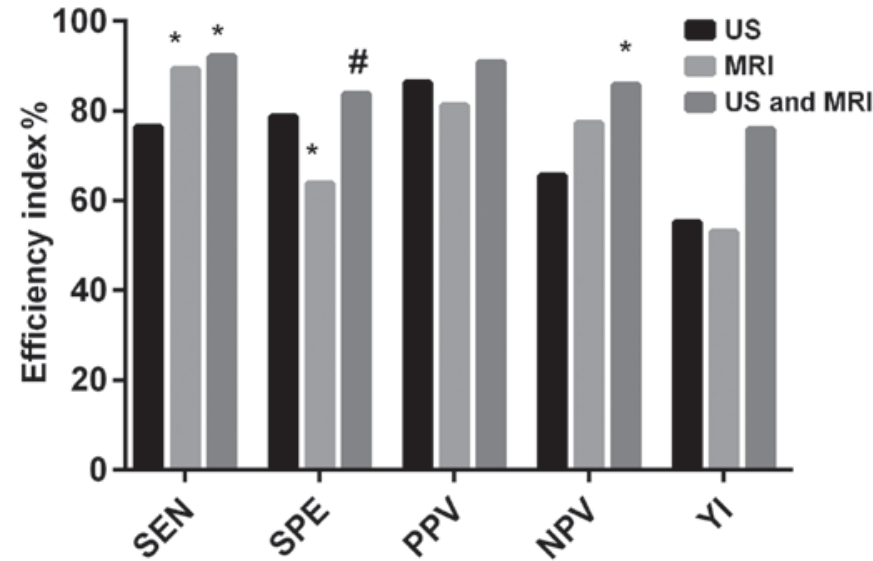

Figure 1. The SEN of MRI alone was not different from that of US combined with MRI ( $P>0.05)$, but that of MRI alone and US combined with MRI was higher than that of US alone $(\mathrm{P}<0.05)$. The SPE of US alone was not different from that of US combined with MRI ( $P>0.05)$, but that of MRI alone was lower than that of US alone and US combined with MRI $(\mathrm{P}<0.05)$. The difference in the PPV among three methods was not statistically significant $(\mathrm{P}>0.05)$. The NPV of US alone and US combined with MRI was not different from that of MRI alone ( $>0.05)$. The NPV of US combined with MRI was significantly higher than that of US alone $(\mathrm{P}<0.05)$. The YI of US combined with MRI was significantly higher than that of US alone and MRI alone, and that of US alone was not significantly different from that of MRI alone. ${ }^{*} \mathrm{P}<0.05$, with the same diagnostic efficacy indicator, compared with US; ${ }^{\prime} \mathrm{P}<0.05$, with the same diagnostic efficacy indicator, compared with MRI.

not significantly different from that of MRI alone (Fig. 1 and Table IV).

Comparison of $T$ staging diagnosis of breast cancer between US and MRI. The evaluation of T staging and pathology of 140 patients before operation was compared among US, MRI and US combined with MRI. The results showed that the difference in the diagnosis of $\mathrm{T} 1$ and $\mathrm{T} 3$ among three methods was not statistically significant $(P>0.05)$, with coincidence rates of $100 \%$ in the evaluation of $\mathrm{T} 4$. In the diagnosis of $\mathrm{T} 2$, the coincidence rates of MRI alone and US combined with MRI were significantly higher than that of US alone $(\mathrm{P}<0.05)$, and that of MRI alone was not significantly different than that of US combined with MRI ( $\mathrm{P}>0.05)$ (Table V).

Comparison of $N$ staging diagnosis of breast cancer between US and MRI. The evaluation of $\mathrm{N}$ staging and pathology of 140 patients before operation was compared among US, MRI and US combined with MRI. The results showed that the difference in $\mathrm{N} 1$ and $\mathrm{N} 3$ among three methods was not statistically significant $(\mathrm{P}>0.05)$. In the evaluation of $\mathrm{N} 0$, the coincidence rates of MRI alone and US combined with MRI were higher than that of US alone $(\mathrm{P}<0.05)$, and that of MRI alone was not different than that of US combined with MRI $(\mathrm{P}>0.05)$. In the diagnosis of $\mathrm{N} 2$, that of US combined with MRI was significantly higher than those of US alone and MRI alone $(\mathrm{P}<0.05)$, and that of MRI alone was not significantly different than that of US alone ( $>0.05)$ (Table VI).

Comparison of $M$ staging diagnosis of breast cancer between US and MRI. The evaluation of M staging and pathology of 140 patients before operation was compared among US, MRI
Table IV. Comparison of SEN, SPE, PPV and NPV among groups.

\begin{tabular}{lccccc}
\hline $\begin{array}{l}\text { Detection } \\
\text { indicators }\end{array}$ & $\begin{array}{c}\text { US } \\
(\%)\end{array}$ & $\begin{array}{c}\text { MRI } \\
(\%)\end{array}$ & $\begin{array}{c}\text { US combined } \\
\text { with MRI }(\%)\end{array}$ & $\chi^{2}$ value & P-value \\
\hline SEN & 76.43 & $89.29^{\mathrm{a}}$ & $92.14^{\mathrm{a}}$ & 16.25 & $<0.001$ \\
SPE & 78.75 & $63.75^{\mathrm{a}}$ & $83.75^{\mathrm{b}}$ & 9.349 & $<0.001$ \\
PPV & 86.29 & 81.17 & 90.85 & 5.746 & 0.057 \\
NPV & 65.63 & 77.27 & $85.90^{\mathrm{a}}$ & 9.709 & 0.008 \\
YI & 55.18 & 53.04 & 75.89 & - & - \\
\hline
\end{tabular}

${ }^{a} \mathrm{P}<0.05$ compared with US. ${ }^{\mathrm{b}} \mathrm{P}<0.05$ compared with MRI.

and US combined with MRI. The results showed that in stages of M0 and M1 among the three methods, the coincidence rates of MRI alone and US combined with MRI were higher than that of US alone $(\mathrm{P}<0.05)$, and that of MRI alone was not significantly different from that of US combined with MRI $(\mathrm{P}>0.05)$ (Table VII).

\section{Discussion}

In recent years, as its incidence occurs at younger age and mortality has gradually increased, breast cancer has become the number one killer threatening female health $(9,10)$. Clinical features of early breast cancer are atypical, with high misdiagnosis and missed diagnosis rates, so most of breast cancer patients are in the advanced stage when diagnosed. At present, there is no clear and effective primary prevention method. Therefore, the early detection and accurate preoperative staging and treatment of breast cancer are crucial to improve the prognosis $(11,12)$. Many studies have been reported on the value of US combined with MRI detection in breast cancer staging, but most of them only focus on $\mathrm{T}$ staging and diagnosis efficiency, few only on $\mathrm{N}$ and $\mathrm{M}$ staging (13). Therefore, in this study, the diagnostic value of US combined with MRI in the T, $\mathrm{N}$ and $\mathrm{M}$ staging of breast cancer was analyzed, in order to provide a more effective, sensitive and accurate detection program for the early diagnosis and accurate staging, improving the efficacy of patients' subsequent treatment and the prognoses.

The positive expression case rates of ER and PR were significantly higher in breast cancer group than those in benign group, but that of Her-2 was significantly lower in breast cancer group than that in benign group. This is consistent with the findings of Li et al (14), in the study of ER, PR and HER-2 expression in breast cancer and their relationship with tumor staging and lymph node metastasis. ER, PR and HER-2 are important indicators for judging the prognosis of the patient.

In the evaluation of breast cancer T staging, US, MRI and US combined with MRI had coincidence rates of $100 \%$ in the evaluation of T4. The coincidence rates of MRI alone and US combined MRI in the diagnosis of T2 were significantly higher than that of US alone, with no statistically significant difference in other stages. The accuracy of MRI and US for tumor lesion and tumor size in newly diagnosed non-high-risk breast cancer patients was compared by Segara et al (15). The 
Table V. Results of breast cancer T staging in US and MRI.

\begin{tabular}{lccrr}
\hline $\begin{array}{l}\text { Pathological } \\
\text { T staging }\end{array}$ & $\begin{array}{c}\text { US consistent with } \\
\text { pathology, }(\%)\end{array}$ & $\begin{array}{c}\text { MRI consistent with } \\
\text { pathology, }(\%)\end{array}$ & $\begin{array}{c}\text { US combined with MRI consistent } \\
\text { with pathology, }(\%)\end{array}$ & $\begin{array}{c}\chi^{2} \text { value } \\
\text { P-value }\end{array}$ \\
\hline T1 $(\mathrm{n}=13)$ & $7(53.85)$ & $10(76.92)$ & $11(84.62)$ & 3.292 \\
T2 $(\mathrm{n}=72)$ & $50(69.44)$ & $62(86.11)^{\mathrm{a}}$ & $64(88.89)^{\mathrm{a}, \mathrm{b}}$ & 0.193 \\
T3 $(\mathrm{n}=44)$ & $39(88.64)$ & $42(95.45)$ & $43(97.73)$ & 0.005 \\
T4 $(\mathrm{n}=11)$ & $11(100.00)$ & $11(100.00)$ & $11(100.00)$ & 0.090 \\
Total $(\mathrm{n}=140)$ & $107(76.43)$ & $125(89.29)^{\mathrm{a}}$ & $129(92.14)^{\mathrm{a}, \mathrm{b}}$ & - \\
\hline
\end{tabular}

${ }^{\mathrm{a}} \mathrm{P}<0.05$ compared with US in the same T staging. ${ }^{\mathrm{b}} \mathrm{P}<0.05$ compared with MRI in the same T staging.

Table VI. Results of breast cancer N staging in US and MRI.

\begin{tabular}{|c|c|c|c|c|c|}
\hline $\begin{array}{l}\text { Pathological } \\
\text { T staging }\end{array}$ & $\begin{array}{l}\text { US consistent with } \\
\text { pathology, n }(\%)\end{array}$ & $\begin{array}{l}\text { MRI consistent with } \\
\text { pathology, n }(\%)\end{array}$ & $\begin{array}{l}\text { US combined with MRI consistent } \\
\text { with pathology, } \mathrm{n}(\%)\end{array}$ & $\chi^{2}$ value & P-value \\
\hline NO $(n=75)$ & $60(80.00)$ & $69(92.00)^{\mathrm{a}}$ & $69(92.00)^{\mathrm{a}}$ & 4.485 & 0.034 \\
\hline N1 $(n=37)$ & $30(81.08)$ & $32(86.49)$ & $34(91.89)$ & 1.850 & 0.397 \\
\hline $\mathrm{N} 2(\mathrm{n}=20)$ & $13(65.00)$ & $17(85.00)$ & $19(95.00)^{\mathrm{a}}$ & 6.234 & 0.044 \\
\hline N3 $(n=8)$ & $4(50.00)$ & $7(87.50)$ & $7(87.50)$ & 4.200 & 0.135 \\
\hline Total $(n=140)$ & $107(76.43)$ & $125(89.29)^{\mathrm{a}}$ & $129(92.14)^{\mathrm{a}}$ & 16.250 & $<0.001$ \\
\hline
\end{tabular}

${ }^{\mathrm{a}} \mathrm{P}<0.05$ compared with US in the same $\mathrm{N}$ staging.

Table VII. Results of breast cancer M staging in US and MRI.

\begin{tabular}{lccrr}
\hline $\begin{array}{l}\text { Pathological } \\
\text { T staging }\end{array}$ & $\begin{array}{c}\text { US consistent with } \\
\text { pathology, }(\%)\end{array}$ & $\begin{array}{c}\text { MRI consistent with } \\
\text { pathology, }(\%)\end{array}$ & $\begin{array}{r}\text { US combined with MRI consistent } \\
\text { with pathology, }(\%)\end{array}$ & $\begin{array}{c}\chi^{2} \text { value } \\
\text { P-value }\end{array}$ \\
\hline M0 (n=124) & $98(79.03)$ & $111(89.52)^{\mathrm{a}}$ & $114(91.94)^{\mathrm{a}}$ & 10.200 \\
M1 (n=16) & $9(56.25)$ & $14(87.50)^{\mathrm{a}}$ & $15(93.75)^{\mathrm{a}}$ & 0.006 \\
Total $(\mathrm{n}=140)$ & $107(76.43)$ & $125(89.29)^{\mathrm{a}}$ & $129(92.14)^{\mathrm{a}}$ & 0.020 \\
\hline
\end{tabular}

${ }^{\mathrm{a}} \mathrm{P}<0.05$ compared with US in the same M staging.

results have shown that the difference in tumor size is not significant between MRI and pathological findings. Among molybdenum palladium, US and MRI, breast cancer size is the most accurate when measured by MRI (15). In the evaluation of breast cancer $\mathrm{N}$ staging, the coincidence rates of MRI alone and US combined with MRI were higher than that of US alone in the evaluation of N0. In the diagnosis of $\mathrm{N} 2$, that of US combined with MRI was significantly higher than those of US alone and MRI alone. In stage N2, the ipsilateral axillary lymph nodes of breast cancer patients were swollen, fused to each other and even adhered to other tissues. Therefore, the key point in the examination is to judge the breast lymph node metastasis and the organ invasion around the breast. MRI soft tissue has high resolution and high field NMR. It can be multi-sequence and multi-angle imaging, more accurate for observing breast lymph nodes and breast circumference. Nevertheless, there are still some difficulties in identifying smaller lymph nodes. After the use of developer, identifying the site and shape of the primary lesion, US can also evaluate the obvious contrast effect between the strong echogenic surface produced by ultrasound shadow agent and the breast structure and the tissue around the breast, so as to significantly improve the image quality and better observe breast conditions. However, the axillary lymph in the stage of $\mathrm{N} 2$ fuse with each other and even adhere to other tissues, causing a certain degree of interference to acoustic shadow, so US examination has certain difficulties $(16,17)$. In stages of M0 and M1 among the three methods, the coincidence rates of MRI alone and US combined with MRI were higher than that of US alone, and that of MRI alone was not significantly different from that of US combined with MRI. Clearly displaying the local irregular thickening of the breast, MRI can determine whether there is tumor invasion and liver metastasis outside the breast, and tumor recurrence. US for observing the hierarchical structure of the breast can determine the depth of lesion invasion and lymph 
node metastasis around the breast, but it may be difficult to distinguish when ulcer or tumor lesions occur $(18,19)$.

In summary, US combined with MRI for the diagnosis of breast cancer has higher SEN and SPE, with better accuracy rate for the identification of each stage. Reducing the incidence of missed diagnosis and misdiagnosis that may be caused by single diagnosis and treatment, it is conducive to clinical screening and guiding clinical symptomatic treatment and worthy of clinical promotion.

\section{Acknowledgements}

Not applicable.

\section{Funding}

This study was supported by the project of Changzhi Medical College Doctoral Scientific Research Start-up Fund (no. BS15002).

\section{Availability of data and materials}

The datasets used and/or analyzed during the present study are available from the corresponding author on reasonable request.

\section{Authors' contributions}

QP was responsible for US examination. JJ analyzed the data of US and MRI examination. Both authors read and approved the final manuscript.

\section{Ethics approval and consent to participate}

The study was approved by the Ethics Committee of Heping Hospital Affiliated to Changzhi Medical College (Changzhi, China). Patients who participated in this study, signed the informed consent and had complete clinical data.

\section{Patient consent for publication}

Not applicable.

\section{Competing interests}

The authors declare that they have no competing interests.

\section{References}

1. Merckel LG, Knuttel FM, Deckers R, van Dalen T, Schubert G, Peters NH, Weits T, van Diest PJ, Mali WP, Vaessen PH, et al: First clinical experience with a dedicated MRI-guided highintensity focused ultrasound system for breast cancer ablation. Eur Radiol 26: 4037-4046, 2016.

2. Onitilo AA, Engel JM, Greenlee RT and Mukesh BN: Breast cancer subtypes based on ER/PR and Her2 expression: Comparison of clinicopathologic features and survival. Clin Med Res 7: 4-13, 2009.

3. Chen Y, Chen K, Xiao X, Nie Y, Qu S, Gong C, Su F and Song E: Pretreatment neutrophil-to-lymphocyte ratio is correlated with response to neoadjuvant chemotherapy as an independent prognostic indicator in breast cancer patients: A retrospective study. BMC Cancer 16: 320, 2016.
4. Keam B, Im SA, Kim HJ, Oh DY, Kim JH, Lee SH, Chie EK, Han W, Kim DW, Moon WK, et al: Prognostic impact of clinicopathologic parameters in stage II/III breast cancer treated with neoadjuvant docetaxel and doxorubicin chemotherapy: Paradoxical features of the triple negative breast cancer. BMC Cancer 7: 203, 2007.

5. Siroy A, Abdul-Karim FW, Miedler J, Fong N, Fu P, Gilmore H and Baar J: MUC1 is expressed at high frequency in earlystage basal-like triple-negative breast cancer. Hum Pathol 44: 2159-2166, 2013.

6. Abe H, Schacht D, Kulkarni K, Shimauchi A, Yamaguchi K, Sennett CA and Jiang Y: Accuracy of axillary lymph node staging in breast cancer patients: An observer-performance study comparison of MRI and ultrasound. Acad Radiol 20: 1399-1404, 2013.

7. Kuhl C, Kuhn W, Braun M and Schild H: Pre-operative staging of breast cancer with breast MRI: One step forward, two steps back? Breast 16 (Suppl 2): S34-S44, 2007.

8. Fouad TM, Barrera AMG, Reuben JM, Lucci A, Woodward WA Stauder MC, Lim B, DeSnyder SM, Arun B, Gildy B, et al: Inflammatory breast cancer: A proposed conceptual shift in the UICC-AJCC TNM staging system. Lancet Oncol 18: e228-e232, 2017.

9. Gahlaut R, Bennett A, Fatayer H, Dall BJ, Sharma N, Velikova G, Perren T, Dodwell D, Lansdown M and Shaaban AM: Effect of neoadjuvant chemotherapy on breast cancer phenotype, ER/PR and HER2 expression - Implications for the practising oncologist. Eur J Cancer 60: 40-48, 2016.

10. Dent R, Trudeau M, Pritchard KI, Hanna WM, Kahn HK, Sawka CA, Lickley LA, Rawlinson E, Sun P and Narod SA: Triple-negative breast cancer: Clinical features and patterns of recurrence. Clin Cancer Res 13: 4429-4434, 2007.

11. Yao ZX, Lu LJ, Wang RJ, Jin LB, Liu SC, Li HY, Ren GS, Wu KN, Wang DL and Kong LQ: Discordance and clinical significance of ER, PR, and HER2 status between primary breast cancer and synchronous axillary lymph node metastasis. Med Oncol 31: 798, 2014.

12. Nik-Zainal S, Davies H, Staaf J, Ramakrishna M, Glodzik D, Zou X, Martincorena I, Alexandrov LB, Martin S, Wedge DC, et al: Landscape of somatic mutations in 560 breast cancer whole-genome sequences. Nature 534: 47-54, 2016.

13. Tseng J, Kyrillos A, Liederbach E, Spear GG, Ecanow J, Wang CH, Czechura T, Kantor O, Miller M, Winchester DJ, et al: Clinical accuracy of preoperative breast MRI for breast cancer. J Surg Oncol 115: 924-931, 2017.

14. Li W, Jia M, Qin X, Hu J, Zhang X and Zhou G: Harmful effect of ER $\beta$ on BCRP-mediated drug resistance and cell proliferation in ER $\alpha / P R$-negative breast cancer. FEBS J 280: 6128-6140, 2013.

15. Segara D, Krop IE, Garber JE, Winer E, Harris L, Bellon JR, Birdwell R, Lester S, Lipsitz S, Iglehart JD, et al: Does MRI predict pathologic tumor response in women with breast cancer undergoing preoperative chemotherapy? J Surg Oncol 96: 474-480, 2007.

16. Heijnsdijk EA, Warner E, Gilbert FJ, Tilanus-Linthorst MM, Evans G, Causer PA, Eeles RA, Kaas R, Draisma G, Ramsay EA, et al: Differences in natural history between breast cancers in BRCA1 and BRCA2 mutation carriers and effects of MRI screening-MRISC, MARIBS, and Canadian studies combined. Cancer Epidemiol Biomarkers Prev 21: 1458-1468, 2012.

17. DeLeo MJ III, Domchek SM, Kontos D, Conant E, Chen J and Weinstein S: Breast MRI fibroglandular volume and parenchymal enhancement in BRCA1 and BRCA2 mutation carriers before and immediately after risk-reducing salpingo-oophorectomy. AJR Am J Roentgenol 204: 669-673, 2015.

18. Rudat V, Nour A, Almuraikhi N, Ghoniemy I, Brune-Erber I, Almasri N and El-Maghraby T: MRI and ultrasonography for assessing multifocal disease and tumor size in breast cancer: Comparison with histopathological results. Gulf J Oncol 1: 65-72, 2015.

19. Partridge SC, Nissan N, Rahbar H, Kitsch AE and Sigmund EE: Diffusion-weighted breast MRI: Clinical applications and emerging techniques. J Magn Reson Imaging 45: 337-355, 2017.

This work is licensed under a Creative Commons Attribution-NonCommercial-NoDerivatives 4.0 International (CC BY-NC-ND 4.0) License. 